more complete demonstration a good deal further illustrating the actual movement, has to be said on that head. Here we have space only for a general outline.

The muscle, of course, has no isolated voluntary action, but its effect is brought into play when the eye brows are forcibly raised by the contraction of the occipito-frontalis. Indeed, although itself really a muscle as described, much of its effect is derived after the fashion of an elastic tendon connected with the great epicranial muscle. It is further assisted by the consentaneous action of certain small muscles of the auricle, notably the attollens auriculam. Its movement is quite perceptible to the finger placed in the sulcus, between the pinna and side of the head, and to an experienced eye its effect on the membrane is distinctly visible through the speculum when the occipito-frontalis is made to contract.

It would be beyond the scope of a single paper to enter into a demonstration of the effect of this movement of the membrana flaccida on the membrane and ossiclesbut it can be shown that, in opposition to the so-called tensor tympani muscle, it helps to bring the umbo or deepest part of the membrane outwards, thus tending to reverse the cone, and bring the membrane generally into a more vertical position, relatively to the lower wall of the meatus. This is beyond all question its position for acutest hearing, and it is thus important to observe that by the single contraction of the occipito frontalis muscle, both eyes and ears are brought simultaneously into the attitudes of strained attention. Hence, in endeavouring to hear as well as to see itently, we involuntarily raise the eyebrows in order to $t: 1$ upon the drum of the ear.

A smart blow administe: $d$ on the side of the head, as is too often thoughtlessly done by schoolmasters and parents in correcting chilvien, may cause sudden spasmodic action of the muscle, and thus, through the action of the mechanism descri $d$, serious injury or even rupture of the drum.

JOHN M. CROMBIE

WEIGHTS AND MEASURES

THE Board of Trade lay before Parliament an Annual Report of their proceedings and business under the Weights and Measures Acts, \&c., and their Report for the current year has just been issued.

It is required by law that the three Parliamentary copies of the Imperial Standards of measure and weight, which are deposited at the Royal Mint with the Royal Society, and in the Royal Observatory, respectively, should be compared with each other once in every ten years. The period for such decennial comparisons having recently arrived the Board took the necessary steps for the removal of these Standards to their office. The methods of comparison adopted and the actual differences between the Standards are shown in a memorandum by $\mathrm{Mr}$. H. J. Chaney, which is attached to the Report. It appears that the comparing apparatus in use at the Standards Office is found to require alteration, a il that in considering the changes necessary to be made the Board have had the valuable assistance of a Committee af the Royal Society, composed of Sir G. Airy, Major-Gen. A. R. Clarke, and Prof. Stokes. It is really important that a department which is charged with the care and use of our national standards, should have the best apparatus, and we trust, therefore, that the Report of the Committee may be speedily and fully carried out.

Reference is also made to the papers issued by the Comité International des Poids et Measures, Paris, and the Report acknowledges the assistance the Standards Department has received from these papers, particularly with reference to the measurement of heat and the determination of volume and weight. This country is the only civilised country which has not joined the Comite International, and taken part officially in their proceedings, although it would appear that it has not failed to avail itself of their labours.
The two ancient standards of the metric system, the Toise du Perou and the Toise du Nord, are stated to be still at the Paris Observatory, in a good state of preservation, as also are the measures used by Borda, Brisson, and Lavoisier. By a decree of the Sultan, the metric system came into force in Turkey on March Ist last, and the equivalents of the old and new Turkish weights and measures are stated in this Report.

The Board have had their attention cirrected to the question of a uniform system of screw threads, as well as to that of a standard wire gauge. Reference is made to the want of uniformity in the system of screw threads used in the construction of scientific and optical instruments. It is hoped that the attention which is now being given to this question may result in the adoption of a standard syst $m$ of screw threads. Any step which tends to lessen the high cost of construction and of repair of scientific apparatus is to be welcomed.

From time to time, as science advances and commerce extends, it is found that new kinds of standards are needed, and the attention of the Department has therefore been this year called to the expediency of adopting new photometric tests for gas, and also as to possible means of measuring electrical energy. In the proposed Bill for amending the enactments for regulating the sale of gas, and of dealing with the mode of testing the illuminating power of gas, we trust that Mr. Vernon Harcourt's new air gas-flame test, on which Dr. Williamson and Dr. Odling have reported, may receive favourable consideration.

Under the Petroleum Acts rules are laid down for determining the "flashing-point" of oils, or the temperature at which they begin to give off inflammable vapours, but it appears by the Report that Dr. Foerster has lately called attention to the omission in these rules of any allowance for variations of atmospheric pressure. The rules in this respect evidently, therefore, require some amendment.

The Report also contains much information valuable to local inspectors and others practically interested in weighing and measuring.

\section{ON THE PROPOSED FORTH BRIDGE}

$\mathrm{I}$ offering some remarks (which I trust may be final) merely explanatory of preceding notes on this proposed structure, I shall refer generally to my letter of October I9 (NATCRE, vol. xxvi. pp. 598-60I).

First, I have to modify the force of my expressions relating to the danger arising from the use of certain long struts to support very heavy end-pressures. My remarks were the consequence of error in the engraved longitudinal vertical plan, circulated (I understood) under the authority of the Official Board. In this plan, by the indiscretion of the engraver, the tubular struts of 340 feet length and 240 feet lengtb respectively, are drawn clearly ind distinctly as unconnected in their entire length with any other braces. In other parts of the plan, each connection of that class is indicated by a rose ; but there is no such mark upon these rods. A person scrutinising the plan might well feel alarm at the prospect of unbraced rods 340 feet long, intended to support end-pressures exceeding 600 tons. But Mr. Fowler has kindly informed me that the plan is erroneous, and that there is connection at each place where the strut crosses a brace, and that the flexible length of the strut is thus reduced to 170 feet. This diminishes the danger of buckling in a vertical plane so greatly that I imagine it may be passed without further notice. Still I remark that the danger of buckling in a horizontal direction, with a length of 340 feet, remains undiminished, unless it is counteracted by bracing not known to me.

In regard to some effects of the wind, the following comparison between the proposed Forth Bridge and the 
late Tay Bridge may be interesting. I suppose that equal trains are upon the two bridges; and I assume thit the force of the wind on the Tay Bridge train tore one pier from its foundation-attachment. (I imagine that the ruin of the bridge commenced thus). The height of the centre of the Tay Bridge train was about 92 feet, and the momentum of the wind was, therefore, wind $\times$ train $\times 92$ feet. (The reader will easily interpret my brief notation). To resist this there were three pairs of attachments to the foundation, with lever-widths of Io feet, 22 feet, ro feet, respectively. So that, supposing the holding powers of each attachment the same, we must have had for momentum of resistance, one Tayattachment $\times(10+22+10)$ feet. At the instant of breakage, this was equal to the momentum of the wind, or to wind $\times$ train $\times 92$ feet. So that one Tay-attachment $=\frac{92}{42} \times$ wind $\times$ train $=2.19 \times$ wind $\times$ train. If we treat the proposed Forth Bridge in the same manner, we must use, length of lever about 660 feet, and two pairs of attachments of the cantilever to the pier (if I read the plan correctly), at distances of 30 and 120 feet. And thus we shall have the equation at a moment of breakage.

One Forth-attachment $\times(30+120)=$ wind $\times$ train $\times$ 660 ; or one Forth-attachment must $=44 \times$ wind $\times$ train, or double that required for the Tay Bridge.

A numerical value (possibly subject to modification) may be given thus:- Suppose the surface of a train to $=3000$ square feet. With the Government scale of $56 \mathrm{lbs}$. for high wind, the lateral pressure $=75$ tons ; and, using leverage numbers as above, one Forth-attachment $=330$ tons. And this is the strain which each attachment must be able to sustain in respect of resistance to the effect of wind upon a train. I imagine that this has been provided, at least in great measure ; but I think it desirable that attention should be called to the magnitude of the forces here concerned.

The able and experienced engineer who has undertaken the prosecution of this great work, will, I am confident, recognise the possibility of serious inconvenience (yet unforeseen) arising from the points to which I bave alluded in NATURE, vol. xxvi. p. 599-the novelty of plan, at least in this country - the magnitude of plan-the want of experience in a rising scale of magnitude. Should the bridge be erected successfully, I can imagine that many difficulties on small points might arise. For instance:-all matter yields to force; the brackets of furlong-length, could not strictly preserve their form under the passage of a train ; the connection of the end of one bracket with the beginning of the next is not very perfect, and I can hardly imagine that trains could be run through at speed (which, as I understood, is one of the conditions to be secured).

I still prefer the principle of suspension. I would propose for further consideration the modifications which I have suggested in NATURE, vol. xxvi. p. 600 , for giving enlarged width with diminished height to the top of the piers, and for use of wire in forming the suspension-chains.

The White House, Greenwich, December 4

\section{NOTES}

MONDAy's sitting of the Paris Academy of Sciences was one of unusual interest. M. Jamin, who was in the chair, delivered an eloquent address on the services rendered to science aud to the Academy by M. Lumas, and presented to the illustrious Per. petual Secretary the medal subscrited for by his admirers as a testimonial on the occasinn of the fiftieth year of his nomination as an academician. The medal is accompanied by ilver and bronze replicas. The whole of the audience, which was very numerous, broke into enthusiastic plaudits. When the enthu- siasm subsided, M. Dumas returned thanks, which he did with masterly eloquence.

WE regret to announce the death of the Rev. James Challis, M.A., F.R.S., Plumian Professor of Astronomy and Fellow of Trinity College, which took place on Sunday morning at his residence in Cambridge, after a long illness. The late Professor was born in 1803, and educated at Trinity College, where he graduated B.A. in 1825 as Senior Wrangler and first Smith's prizeman. In 1836 he was elected Plumian Professor of Astronomy in succession to Mr. (now Sir) G. B. Airy, and also held the important post of Director of the Cambridge Observatory. The latter post he resigned in $186 \mathbf{I}$, and was succeeded by Prof. Adams. He was at the time of his death the Senior of the Professors at Cambridge, and until about two years ago personally discharged the duties of his professorship, when increas. ing age and infirmities compelled him to appoint a deputy. Prof. Challis has published a con:iderable number of scientific works, including twelve volumes of astronomical observations.

THE death is announced of Dr. Gustave Svanberg, formerly Professor of Astronomy and Director of the Observatory of Upsala University. He died on November 21, in his eightyfirst year.

News from Aden reports the death of Marchese Orazio Antinori, the well-known zoologist and African traveller, who had recently started on a new expedition to the Upper Nile. He was seventy-one years of age.

ELABORATE preparations were made in various parts of America to observe the transit of Venus yesterday. The Western Union Telegraph, to facilitate observations, arranged to transmit Washington time wherever desired, in order to secure accuracy in recording results. Some enthusiastic astronomers had proposed general prayer in the churches on Sunday last for clear weather.

M. W. DE Fonvielle has published the first number of a new astronomical journal, called "Les Passages de Venus," which explains the great astronomical event, and is being sold in the streets of Paris at I sou, with illustrations indicating the phase:, and giving instructions for their observation in France. The editor states that he trusts that the second number will appear at the right date, June 8, 2004, and the third in June, 2012, and so on, as long as there will be on the earth rational beings intelligent enough to take an interest in the transit of Venus. He congratulates himself on having established a "periodical" which will be perhaps the most durable foundation of his age.

A Swiss Geological Society has lately been formed. It is an offshoot from the Helvetic Society of Natural Sciences. While a permanent section of this, it will have its own life, its committee, its funds, its distinct séances, and its publications if thought desirable. It will have members who do not belong to the mother society; will send a delegate to the preparatory assembly of the latter, and will have the right of presentation of members. The number of adhereits of the new society is already over sixty.. It has absurbed the Congress der Feld Geologen and the Comité d' Unification géologique. Among other things it will encourage excursions along with discussion on the ground, and will represent Switzerland in the International Geological Congresses. The Society has testified its respect for MM. Studen, Heer, and Merian, by (exceptionally) giving them the title of Honorary Members.

THE Council of the British Association, acting under the powers conferred upon them by the General Committee, in accordance with their Report, have appointed the following to be a Committee, "to draw up snggestions uron methcds of more 